\title{
Coaching, Mentoring, and Sponsoring as Career Development Tools
}

Dean A. Seehusen, MD, MPH; Tyler S. Rogers, MD; Morhaf Al Achkar, MD, PhD; Tammy Chang, MD, MPH, MS

\begin{abstract}
BACKGROUND AND OBJECTIVES: Coaching, mentoring, and sponsoring are tools academic leaders can utilize to develop junior faculty. Each tool has a unique goal, time frame and method. It has been suggested that sponsoring may be a particularly useful tool for furthering the careers of women in medicine. Our primary aim was to understand to what extent one group of academic leaders - family medicine department chairs-have benefited from each tool in their own career development and how often they use each to develop others. A secondary aim was to compare women's experiences with sponsorship to their male colleagues.
\end{abstract}

METHODS: We surveyed all US family medicine department chairs electronically about their experiences with coaching, mentoring, and sponsoring. We collected data from August 2019 to October 2019.

RESULTS: One hundred five of 193 family medicine department chairs responded to our survey (54.4\% response rate). Most indicated that mentoring played a significant role in their career development, with fewer reporting coaching and sponsorship played significant roles. More reported frequent use of mentoring to develop faculty compared to coaching or sponsoring. Training in mentoring and sponsoring was associated with increased use, but coaching was not. No gender difference was found in this study population.

CONCLUSIONS: Chairs have less experience with coaching and sponsoring than mentoring. Personal experience being coached, mentored, or sponsored was associated with increased use of these tools. Formal training may increase use of mentoring and sponsoring. Contrary to our hypothesis, female chairs' experience with sponsoring was similar to their male peers.

(Fam Med. 2021;53(3):175-80.)

doi: 10.22454/FamMed.2021.341047

A critical task of leaders in academic medicine is to help junior faculty build successful academic careers..$^{1-3}$ Many methods are available to leaders to help develop junior faculty including coaching, ${ }^{4}$ mentoring, ${ }^{5}$ and sponsoring ${ }^{6}$. Extensive literature has been published about mentoring. ${ }^{6,7}$ More recently, coaching and sponsoring have received attention as distinct ways that more experienced individuals can help improve, develop, and advance junior faculty. 4,8

Coaching, mentoring, and sponsoring differ in their specific goal, time frame, and methodology. The existing literature does not use consensus definitions, and there is a degree of overlap in the concepts. There is enough agreement about what the concepts mean to view them as distinct entities. Table 1 compares key features of these three tools based on the existing literature. ${ }^{4-6,9}$ Using all three tools in the appropriate setting and in a complementary fashion is likely to achieve the greatest overall development of academic faculty.

Coaching is typically viewed as a periodic practice. Lovell highlights that it is often iterative in nature, following an "observe, provide feedback, reobserve" for the coach. From the standpoint of the coached, this is a "perform, receive feedback, reperform" cycle. ${ }^{4}$ The goal of coaching is to improve the performance of a relatively isolated task, skill, or activity to reach a predefined goal, ${ }^{10}$ and has shown the most promise for technical skills. It may also have a positive impact on physician well-being. ${ }^{4}$

Mentoring is classically a longitudinal process aimed at career development through dialogue-based guidance. ${ }^{7,11}$ Research supports the benefits of mentoring, including personal development, research productivity, and grant success. ${ }^{7} \mathrm{~A}$ wide range of models of mentorship have been studied with most relying on

From the Department of Family Medicine at Augusta University, Augusta, GA (Dr Seehusen); Madigan Army Medical Center, Tacoma, WA (Dr Rogers); Department of Family Medicine, University of Washington, Seattle, WA (Dr Al Achkar); and the Institute for Healthcare Policy \& Innovation, University of Michigan (Dr Chang). 
Table 1: Three Tools for Developing Junior Faculty in Academic Medicine: Coaching, Mentoring, and Sponsoring

\begin{tabular}{|l|l|l|l|}
\hline & \multicolumn{1}{|c|}{ Coaching } & \multicolumn{1}{c|}{ Mentoring } & \multicolumn{1}{c|}{ Sponsoring } \\
\hline Goal & $\begin{array}{l}\text { Skill } \\
\text { improvement }\end{array}$ & Career guidance & $\begin{array}{l}\text { Career } \\
\text { advancement }\end{array}$ \\
\hline Time frame & Periodic & Longitudinal & Episodic \\
\hline Method & $\begin{array}{l}\text { Focused } \\
\text { instruction }\end{array}$ & $\begin{array}{l}\text { Broad-based } \\
\text { dialogue }\end{array}$ & Specific advocacy \\
\hline
\end{tabular}

Each tool has a unique typical purpose, time frame, and methodology.

a mentor giving advice and suggestions to a mentee. The outcomes of a mentoring relationship are less specific initially, although broad goals are often identified. ${ }^{11}$

Sponsoring has only recently been viewed as a potentially important ingredient to career development in academic medicine., ${ }^{42}$ Sponsorship may be an isolated episode or a sequence of actions in which an individual provides sponsorship over the course of many years. The explicit goal of sponsorship is career advancement for the sponsored. ${ }^{6}$ Much of the existing literature theorizes that sponsorship may be more important for women than men. ${ }^{6,13}$ Sponsoring is seen as a possible way to address the ongoing gender gap in academic medical leadership. 9,14 This notion was recently challenged when Patton et al found that sponsorship appeared to have a greater benefit for male than female National Institutes of Health grantees. ${ }^{15}$

Most of the existing literature treats these three development tools in isolation, with little work having been done comparing these methods. It would be useful to understand how academic physicians who have achieved significant career success perceive the relative impact of these methods on their careers. It would also be valuable to understand how current leaders utilize these tools when developing others. Additionally, it would be useful to understand if the lived experience of female academic medicine leaders regarding sponsoring matches the theoretical importance placed on it in the literature.
The purpose of this study was to define the experiences of family medicine chairs with these three development tools. Our aim was to assess how these developmental tools impacted their careers, how frequently chairs employ these methods to develop faculty, and factors associated with the use of these tools by chairs. A secondary aim was to assess the sponsoring experience of female chairs compared to male chairs.

\section{Methods}

A survey containing 11 demographic questions and 12 original questions about coaching, mentoring, and sponsoring was sent to family medicine department chairs as part of a larger online omnibus survey conducted by the Council of Academic Family Medicine Educational Research Alliance (CERA). ${ }^{16}$ The overall survey was produced and conducted utilizing the standard CERA survey methodology described elsewhere. ${ }^{17}$ These methods include evaluating questions for consistency with the overall subproject aim, readability, and existing evidence of reliability and validity. Pretesting was done on family medicine educators who were not part of the target population. We modified questions following pretesting for flow, timing, and readability, and also clarity and readability as a result of this piloting. The American Academy of Family Physicians Institutional Review Board approved this project in August 2019. Data were collected from August 2019 to October 2019.

The survey sampling frame was US family medicine department chairs, as identified by the
Association of Departments of Family Medicine, an organization made up entirely of family medicine chairs. Email invitations to participate were delivered with the survey utilizing the online program SurveyMonkey. Four follow-up emails to encourage nonrespondents to participate were sent after the initial email invitation.

The authors developed the following definitions of coaching, mentoring, and sponsoring based on review of the literature. We provided these definitions for respondents to view while they completed the survey:

Coaching: Periodic specific feedback provided for the purpose of improving performance on an isolated professional task, action, or activity

Mentoring: A longitudinal relationship in which guidance and advice is given for the purpose of professional development

Sponsoring: Episodic public support by an influential person for the purpose of professional advancement

We conducted descriptive statistics of the results to compare relative frequencies of the chairs' experiences with the three tools. We performed $\chi^{2}$ analyses to understand associations between variables; we set statistical significance at $P<.05$.

\section{Results}

We identified two hundred department chairs at the time of the survey; one email could not be delivered, and six emails had opted out of SurveyMonkey surveys. The final sample size was 193 . The response rate for the survey was $54.4 \%$ (105/193). The majority of respondents were men, and almost half were between the ages of 60 and 69 years (Table 2). Nearly $80 \%$ identified as White. Approximately half of respondents were based at a medical school or academic medical center with the rest being community based. Nearly half of respondents had national leadership experience, while the fewer had 
Table 2: Demographics of Respondents

\begin{tabular}{|c|c|}
\hline Gender $(n=99)$ & n (\%) \\
\hline Female & $35(35)$ \\
\hline Male & $61(62)$ \\
\hline Chose not to disclose & $3(3)$ \\
\hline \multicolumn{2}{|c|}{ Age in Years $(n=99)$} \\
\hline $40-49$ & $16(16)$ \\
\hline $50-59$ & $36(36)$ \\
\hline $60-69$ & $44(44)$ \\
\hline $70+$ & $3(3)$ \\
\hline \multicolumn{2}{|c|}{ Race $(n=98)$} \\
\hline American Indian or Alaska Native & $1(1)$ \\
\hline Asian & $7(7)$ \\
\hline Black or African American & $6(6)$ \\
\hline White & $77(79)$ \\
\hline Chose not to disclose & $7(7)$ \\
\hline \multicolumn{2}{|c|}{ Medical School Based $(n=98)$} \\
\hline Yes & $46(47)$ \\
\hline No & $52(53)$ \\
\hline \multicolumn{2}{|c|}{ Highest Leadership Position Attainted ( $\mathrm{n}=89$ ) } \\
\hline Institutional & $26(29)$ \\
\hline State & $14(16)$ \\
\hline Regional & $2(2)$ \\
\hline National & $42(47)$ \\
\hline International & $5(6)$ \\
\hline
\end{tabular}

institutional, state-wide, or international leadership experience.

Table 3 represents the chairs' reported personal experience with these tools. More of the chairs indicated that mentoring played a significant role in their own professional development than coaching and sponsoring. Most reported that of the three tools, mentoring had played the largest role in their own professional development. Twothirds of the chairs indicated they had received formal training in mentoring, while just under half had received formal training in coaching, and only one-fourth had received formal training in sponsoring.

When asked about their use of these tools, almost all reported that they frequently or very frequently used mentoring to develop faculty. Fewer reported frequent or very frequent use of coaching or sponsoring to develop others. There were no significant differences in impact, frequency, importance, or training in sponsorship by gender (Table 4).

In bivariate analysis (Table 5), chairs who reported benefiting significantly from one of the three developmental tools in their own career were more likely to use that tool frequently to develop faculty compared to those who did not report having significantly benefited from the tool. This alignment was true for coaching, mentoring, and sponsoring. Chairs who reported receiving formal training in mentoring and sponsoring were more likely to use these tools frequently themselves compared to those who did not report such training. The same relationship was not found for coaching. 
Table 3: Respondents' Experience With Coaching, Mentoring, and Sponsorship

\begin{tabular}{|c|c|c|c|}
\hline \multicolumn{4}{|c|}{ This Developmental Tool Played a Significant Role in Their Own Professional Development } \\
\hline \multirow[b]{2}{*}{ Tool } & \multicolumn{3}{|c|}{ Agreed or Strongly Agreed (\%) } \\
\hline & Total & Male & Female \\
\hline Coaching & $59(66.3)$ & $33(61.1)$ & $26(78.8)$ \\
\hline Mentoring & $70(78.7)$ & $42(75.9)$ & $28(85.8)$ \\
\hline Sponsoring & $44(49.4)$ & $27(50.0)$ & $16(48.5)$ \\
\hline \multicolumn{4}{|c|}{ Developmental Tool That Played the Largest Role in Their Personal Development Into an Academic Leader } \\
\hline & \multicolumn{3}{|c|}{ Yes (\%) } \\
\hline Tool & Total & Male & Female \\
\hline Coaching & $18(20.2)$ & $8(14.8)$ & $10(30.3)$ \\
\hline Mentoring & $58(65.2)$ & $38(70.4)$ & $18(54.5)$ \\
\hline Sponsoring & $13(14.6)$ & $8(14.8)$ & $5(15.2)$ \\
\hline \multicolumn{4}{|c|}{ Had Received Training on How to Use This Developmental Tool } \\
\hline & \multicolumn{3}{|c|}{ Yes (\%) } \\
\hline Tool & Total & Male & Female \\
\hline Coaching & $40(44.9)$ & $20(37.0)$ & $20(60.6)$ \\
\hline Mentoring & $59(67.0)$ & $36(66.7)$ & $22(68.8)$ \\
\hline Sponsoring & $23(26.1)$ & $14(25.9)$ & $9(28.1)$ \\
\hline \multicolumn{4}{|c|}{ Frequently Use This Developmental Tool to Support the Development of Faculty } \\
\hline & \multicolumn{3}{|c|}{ Frequently or Very Frequently (\%) } \\
\hline Tool & Total & Male & Female \\
\hline Coaching & $69(77.5)$ & $42(77.8)$ & $26(78.8)$ \\
\hline Mentoring & $81(91.0)$ & $49(90.7)$ & $30(90.9)$ \\
\hline Sponsoring & $48(53.9)$ & $30(55.6)$ & $18(54.5)$ \\
\hline
\end{tabular}

Total, male, and female results are presented. The columns do not always add up to the total because three respondents chose not to disclose their gender.

likelihood of using that tool to develop others. This suggests that current academic leaders should attempt to use all of these tools in a balanced manner when working on career development, so that tomorrow's leaders will use them.

Training was associated with more frequent use of mentoring and sponsoring, but not coaching. While the cross-sectional nature of this study did not allow a determination of causality, it is logical to conclude that training led to increased use. It is possible, however, that those chairs who use mentoring and sponsoring frequently also actively seek out training on these topics. It is unclear why training in coaching was not associated with an increased use. This may be a result of an overall small sample size.
Among survey respondents, there was no evidence that women have a different experience from men when it comes to sponsoring. This finding is somewhat surprising given that sponsoring has been specifically referenced in the literature as a way to advance the careers of women in academic medicine. Therefore, the authors expected that women who have attained a prominent academic position would have received more sponsoring in their careers. However, much of the literature suggesting this use has spoken of the idea theoretically, citing little specific research, because little exists..$^{6,9,18}$ It is possible that such a difference does indeed exist among women in academic medicine who have not yet achieved a position such as chair of a department, but is not present at the level of department chairs. The chairs in our survey were relatively older, supporting this notion. It is also possible that this study's sample did not include enough women to detect subtle differences in their experiences. A post hoc analysis showed that the study had inadequate power to detect small difference in responses between males and females.

Our study has some specific strengths including a relatively high response rate for a survey of department chairs. This is the first study to compare academic leaders' personal experiences with these three developmental tools to one another. The study also has limitations, including that only one specialty, and only one leadership position within that specialty, was represented in the sample. The experience of other specialties, and academic leaders in a position other than department chair 
Table 4: The Sponsoring Experiences of Women vs Men

\begin{tabular}{|c|c|c|c|}
\hline \multicolumn{4}{|c|}{ Sponsorship Played a Significant Role in Their Own Professional Development } \\
\hline & Agreed (\%) & Did Not Agree (\%) & $P$ Value \\
\hline Male & $27(50.0)$ & $27(50.0)$ & .89 \\
\hline Female & $16(48.5)$ & $17(51.5)$ & \\
\hline \multicolumn{4}{|c|}{ Sponsorship Was the Most Important Developmental Tool in Their Own Careers } \\
\hline & Agreed (\%) & Did Not Agree (\%) & $P$ Value \\
\hline Male & $8(14.8)$ & $46(85.2)$ & .60 \\
\hline Female & $5(15.2)$ & $28(84.8)$ & \\
\hline \multicolumn{4}{|c|}{ Had Received Training in Sponsoring } \\
\hline & Agreed (\%) & Did Not Agree (\%) & $P$ Value \\
\hline Male & $14(25.9)$ & $40(74.1)$ & .82 \\
\hline Female & $9(28.1)$ & $23(71.9)$ & \\
\hline \multicolumn{4}{|c|}{ Frequency of Using Sponsorship to Develop Faculty } \\
\hline & Frequently (\%) & Infrequently (\%) & $P$ Value \\
\hline Male & $30(55.6)$ & $24(44.4)$ & .93 \\
\hline Female & $18(54.5)$ & $15(45.5)$ & \\
\hline \multicolumn{4}{|c|}{ Gender of the Individual Who Provided Them the Most Sponsorship in Their Careers } \\
\hline & Male Sponsor (\%) & Female Sponsor (\%) & $P$ Value \\
\hline Male & $32(80.0)$ & $8(20.0)$ & .23 \\
\hline Female & $16(66.7)$ & 8 (33.3) & \\
\hline
\end{tabular}

Table 5: Relationship Between Personal Experience or Training and Use of Coaching, Mentoring, Sponsoring

\begin{tabular}{|c|c|c|c|}
\hline \multicolumn{4}{|c|}{$\begin{array}{c}\text { Relationship Between Significance of Coaching in Own Professional Development } \\
\text { and Frequency of Using Coaching to Develop Faculty }\end{array}$} \\
\hline & $\begin{array}{l}\text { Infrequently Use } \\
\text { Coaching (\%) }\end{array}$ & $\begin{array}{l}\text { Frequently Use } \\
\text { Coaching (\%) }\end{array}$ & $P$ Value \\
\hline Coaching played significant role & $8(13.6)$ & $51(86.4)$ & $.005^{\mathrm{a}}$ \\
\hline Coaching did not play a significant role & $12(40.0)$ & $18(60.0)$ & \\
\hline \multicolumn{4}{|c|}{$\begin{array}{c}\text { Relationship Between Significance of Mentoring in Own Professional Development } \\
\text { and Frequency of Using Mentoring to Develop Faculty }\end{array}$} \\
\hline & $\begin{array}{l}\text { Infrequently Use } \\
\text { Mentoring (\%) }\end{array}$ & $\begin{array}{l}\text { Frequently Use } \\
\text { Mentoring (\%) }\end{array}$ & $P$ Value \\
\hline Mentoring played significant role & $4(5.7)$ & $15(94.3)$ & $.04^{\mathrm{a}}$ \\
\hline Mentoring did not play a significant role & $4(21.1)$ & $66(78.9)$ & \\
\hline \multicolumn{4}{|c|}{$\begin{array}{c}\text { Relationship Between Significance of Sponsoring in Own Professional Development } \\
\text { and Frequency of Using Sponsoring to Develop Faculty }\end{array}$} \\
\hline & $\begin{array}{l}\text { Infrequently Use } \\
\text { Sponsoring (\%) }\end{array}$ & $\begin{array}{l}\text { Frequently Use } \\
\text { Sponsoring (\%) }\end{array}$ & $P$ Value \\
\hline Sponsoring played significant role & 7 (15.9) & $37(84.1)$ & $<.001^{\mathrm{a}}$ \\
\hline Sponsoring did not play a significant role & $34(75.6)$ & $11(24.4)$ & \\
\hline \multicolumn{4}{|c|}{ Relationship Between Having Received Training in Coaching and Frequency of Using Coaching to Develop Faculty } \\
\hline & $\begin{array}{l}\text { Infrequently Use } \\
\text { Coaching (\%) }\end{array}$ & $\begin{array}{l}\text { Frequently use } \\
\text { Coaching (\%) }\end{array}$ & $P$ Value \\
\hline Had received training in coaching & $7(17.5)$ & $33(82.5)$ & .31 \\
\hline Had not received training in coaching & $13(26.5)$ & $36(73.5)$ & \\
\hline
\end{tabular}

(continued on next page) 
Table 5: Continued

\begin{tabular}{|c|c|c|c|}
\hline \multicolumn{4}{|c|}{ Relationship Between Having Received Training in Mentoring and Frequency of Using Mentoring to Develop Faculty } \\
\hline & $\begin{array}{l}\text { Infrequently Use } \\
\text { Mentoring (\%) }\end{array}$ & $\begin{array}{l}\text { Frequently Use } \\
\text { Mentoring (\%) }\end{array}$ & $P$ Value \\
\hline Had received training in mentoring & $2(3.4)$ & $57(96.6)$ & $0.01^{\mathrm{a}}$ \\
\hline Had not received training in mentoring & $6(20.7)$ & $23(79.3)$ & \\
\hline \multicolumn{4}{|c|}{ Relationship Between Having Received Training in Sponsoring and Frequency of Using Sponsoring to Develop Faculty } \\
\hline & $\begin{array}{l}\text { Infrequently Use } \\
\text { Sponsoring (\%) }\end{array}$ & $\begin{array}{l}\text { Frequently Use } \\
\text { Sponsoring (\%) }\end{array}$ & $P$ Value \\
\hline Had received training in sponsoring & $4(17.4)$ & $19(82.6)$ & $0.001^{\mathrm{a}}$ \\
\hline Had not received training in sponsoring & $37(56.9)$ & $28(43.1)$ & \\
\hline
\end{tabular}

a Statistically significant finding

may be different. Perhaps sponsorship is more important for women in specialties that have historically been more male-dominated than family medicine. It is possible that even given definitions, not all survey respondents share a view of what these three terms mean. Gender options in the survey included: "male," "female," "other," and "choose not to disclose." No specific transgender options were given. All cross-sectional surveys are subject to biases such as recall bias and desirability bias. Only association, and not causation, can be shown with this methodology.

Family medicine chairs report that mentoring has been more important in their career development than coaching or sponsoring. They also use mentoring more frequently to develop others. At least for mentoring and sponsoring, formal training is associated with more frequent use. Future research should evaluate whether training that teaches coaching, mentoring, and sponsorship as distinct and complementary tools positively impacts career development. Future research should also investigate how to use these three tools in a coordinated way to maximize their impact on academic career development.

DISCLAIMER: The views expressed in this manuscript are the authors and do not reflect official view of the United States Army, Department of Defense, or the United States Government.
CORRESPONDING AUTHOR: Address correspondence to Dr Dean A. Seehusen, Associate Dean for Graduate Medical Education, Professor of Family Medicine, Augusta University, 1120 15th St, AE 3046, Augusta, GA 30912. 706-723-4385. dseehusen@augusta.edu.

\section{References}

1. Peterson LE, Blackburn B, Phillips RL Jr, Mainous AG III. Family Medicine department chairs' opinions regarding scope of practice. Acad Med. 2015;90(12):1691-1697. doi:10.1097/ ACM.0000000000000774

2. Keith SJ, Buckley PF. Leadership experiences and characteristics of chairs of academic departments of psychiatry. Acad Psychiatry. 2011;35(2):118-121. doi:10.1176/appi. ap.35.2.118

3. Bailey DN, Lipscomb MF, Gorstein F, Wilkinson D, Sanfilippo F. Life after being a pathology department chair II: lessons Learned. Acad Pathol. 2017;4:2374289517733734. doi:10.1177/2374289517733734

4. Lovell B. What do we know about coaching in medical education? A literature review. Med Educ. 2018;52(4):376-390. doi:10.1111/ medu. 13482

5. Sambunjak D, Straus SE, Marusi冈 A. Mentoring in academic medicine: a systematic review. JAMA. 2006;296(9):1103-1115. doi:10.1001/ jama.296.9.1103

6. Travis EL, Doty L, Helitzer DL. Sponsorship: a path to the academic medicine C-suite for women faculty? Acad Med. 2013;88(10):14141417. doi:10.1097/ACM.0b013e3182a35456

7. Geraci SA, Thigpen SC. A Review of Mentoring in Academic Medicine. Am J Med Sci. 2017;353(2):151-157. doi:10.1016/j.amjms.2016.12.002

8. Ayyala MS, Skarupski K, Bodurtha JN, et al. Mentorship is not enough: exploring sponsorship and its role in career advancement in academic medicine. Acad Med. 2019;94(1):94100. doi:10.1097/ACM.0000000000002398

9. Deiorio NM, Carney PA, Kahl LE, Bonura EM, Juve AM. Coaching: a new model for academic and career achievement. Med Educ Online. 2016;21(1):33480. doi:10.3402/meo.v21.33480
10. Sambunjak D, Straus SE, Marusic A. A systematic review of qualitative research on the meaning and characteristics of mentoring in academic medicine. J Gen Intern Med. 2010;25(1):72-78. doi:10.1007/s11606-009-11658

11. Gottlieb AS, Travis EL. Rationale and models for career advancement sponsorship in academic medicine: The Time Is Here; the Time Is Now. Acad Med. 2018;93(11):1620-1623. doi:10.1097/ACM.0000000000002342

12. Ellinas EH, Kaljo K, Patitucci TN, Novalija J, Byars-Winston A, Fouad NA. No Room to "lean in": a qualitative study on gendered barriers to promotion and leadership. J Womens Health (Larchmt). 2018; Epub ahead of print. doi:10.1089/jwh.2018.7252

13. Bickel J, Wara D, Atkinson BF, et al; Association of American Medical Colleges Project Implementation Committee. Increasing women's leadership in academic medicine: report of the AAMC Project Implementation Committee. Acad Med. 2002;77(10):1043-1061. doi:10.1097/00001888-200210000-00023

14. Carnes M, Morrissey C, Geller SE. Women's health and women's leadership in academic medicine: hitting the same glass ceiling? J Womens Health (Larchmt). 2008;17(9):14531462. doi:10.1089/jwh.2007.0688

15. Patton EW, Griffith KA, Jones RD, Stewart A, Ubel PA, Jagsi R. Differences in mentor-mentee sponsorship in male vs female recipients of National Institutes of Health grants. JAMA Intern Med. 2017;177(4):580-582. doi:10.1001/ jamainternmed.2016.9391

16. Shokar N, Bergus G, Bazemore A, et al. Calling all scholars to the council of academic family medicine educational research alliance (CERA). Ann Fam Med. 2011;9(4):372-373. doi:10.1370/afm.1283

17. Seehusen DA, Mainous AG III, Chessman AW. Creating a centralized infrastructure to facilitate medical education research. Ann Fam Med. 2018;16(3):257-260. doi:10.1370/afm.2228

18. Roy B, Gottlieb AS. The career advising program: a strategy to achieve gender equity in academic medicine. J Gen Intern Med. 2017;32(6):601-602. doi:10.1007/s11606-0163969-7 